\title{
Comparison of Nondestructive Testing Methods on Detection of Delaminations in Composites
}

\author{
Liang Cheng ${ }^{1}$ and Gui Yun Tian ${ }^{1,2}$ \\ ${ }^{1}$ School of Electrical, Electronic and Computer Engineering, Newcastle University, Newcastle upon Tyne, NE1 7RU, UK \\ ${ }^{2}$ School of Automation, Nanjing University of Aeronautics and Astronautics, Nanjing 210016, China \\ Correspondence should be addressed to Liang Cheng, liang.cheng@ncl.ac.uk
}

Received 3 November 2011; Accepted 31 January 2012

Academic Editor: B. P. C. Rao

Copyright ( $\odot 2012$ L. Cheng and G. Y. Tian. This is an open access article distributed under the Creative Commons Attribution License, which permits unrestricted use, distribution, and reproduction in any medium, provided the original work is properly cited.

\begin{abstract}
Delamination is one of the most common defects in carbon fibre reinforced plastic (CFRP) components, such as those used in aircraft and wind turbine blades. To detect delaminations, different NDT methods such as ultrasonic (UT), eddy current (EC) scanning, flash thermography, and recent developed pulsed-eddy-current-(PEC-) simulated thermography are conducted for comparison and evaluation of the new developed PEC thermography system at Nanjing University of Aeronautics and Astronautics (NUAA), China through UK-China collaboration. A PEC-stimulated thermography system is built at NUAA, extended from previous joint work between Newcastle and Bath Universities. Using these NDT systems, man-made, dedicated delaminations with varied diameters and depths are investigated and studied. Through this comparison, PEC-stumilated and flash thermography show relatively good indications of the shape of delaminations. The joint studies also show that PEC-stimulated thermography has unique advantage for fibre orientation evaluation.
\end{abstract}

\section{Introduction}

A composite material can be defined as a combination of two and more materials with very different mechanical, thermal, and electrical properties. Due to the low weight and high strength of composites, they are popular for use in aircraft and wind turbine blades. Delamination is one of the most common defects for composite materials. It leads to the degradation of mechanical properties and also causes the failure of the overall composite component. To detect delaminations and ensure the safe operation of composite components, nondestructive evaluation (NDE) techniques are used during both manufacturing and operation of the materials. For NDE of CFRP, a series of specific methods are in continuing development to increase the probability of fault detection at a high-confidence level.

The multilayered structure of CFRP allows the use of Lamb waves [1-4] with good results for the qualitative evaluation of CFRP materials. X-ray methods are also used [5], along with acoustic emission techniques $[6,7]$. Because carbon fibres are electrically conductive, for the nondestructive evaluation of CFRP, electromagnetic methods such as those based on eddy currents $[8,9]$ and microwaves $[10]$ can be used.

An extremely promising technique is thermography, which has the advantage of good fault detection possibility along with the capacity to inspect a large area within a short time. Thermography is also applicable to a wide range of materials, including glass fibre, carbon fibre composites, and metallic materials, where specific excitation techniques are needed for each application. To inspect defects over a large scale and at large stand-off distances, integration of thermography and other NDE approaches have been investigated [11-15], for example, flash thermography [16-18], vibrothermography, sonic thermography, laser thermography, and pulsed-eddy-current-(PEC-) stimulated thermography.

In the case of CFRP, PEC-stimulated thermography can be applied with good results [19]. Carbon fibres present good electrical and thermal conductivity along the fibre to reach the required mechanical parameters; designers use 
either several carbon fibres layers or separate carbon fibres woven together. In general, the fibres from a layer are preimpregnated with polymer resins, forming a lamina that can have uniaxial electrical and thermal anisotropy or biaxial in the case of woven satin carbon fibre. Moreover, CFRP composites will have higher electrical conductivity along the direction of carbon fibres and lower conductivity perpendicular to the fibres in the lamina plane and crosslayer.

PEC-stimulated thermography, combining PEC and thermography, involves the application of a high current electromagnetic pulse to the conductive material under inspection for a short period. In this paper, eddy currents will be induced in the material, leading to the heating of the material itself. The existence of any defects distorts the propagation of the eddy current leading to a variation in material temperature that can be emphasised with thermography. After the period of eddy current heating, the nonhomogeneities of CFRP in the cooling phase also affect the diffusion of heat. Therefore, the mixed phenomena of induction heating dominating in the heating phase and the diffusion of this dominating in the cooling phase and their specific behaviours are useful for the quantitative nondestructive evaluation of a given material's non-homogeneities. Based on recent development at Newcastle and Bath in collaboration with Rolls Royce and Alstom [19], a new low cost and portable PEC-stimulated thermography system is built at NUAA to evaluate the composites and metallic object used in wind or aerospace industry, particularly delamination in composite in this paper. PEC-stimulated thermography has been used to inspect metallic parts in previous studies [20-22]. The temperature distribution around a crack with different penetration depths using FEM modelling has been investigated in [21] and compared with experimental measurements on metallic materials. The results showed that lower temperatures are exhibited at the surface edge of a crack and higher temperatures at the bottom in nonmagnetic materials with a large penetration depth. From previous work in [23], PEC-stimulated thermography was proposed and extended from the surface detection of cracks in metallic parts to the detection of surface discontinuities in CFRP composites, via numerical simulation and experiments. However, other types of defects in composite materials were rarely investigated. Ramdane et al. [24] detected inserted delaminations using induction heating thermography. The experimental studies were undertaken in transmission mode (the inductor and infrared camera are on the different sides of the sample), which is normally not applicable in the in situ inspection. Moreover, the inspection period is around 80 seconds.

In this paper, delaminations within CFRP composites are investigated using PEC-stimulated thermography in reflection mode (the inductor and infrared camera are on the same side of the sample) aiming to reduce the inspection period significantly. In addition, the PEC-stimulated thermography results are compared with other widely used methods such as ultrasonic and flash thermography. The rest of the paper is organised as follows. Section 2 introduces the samples

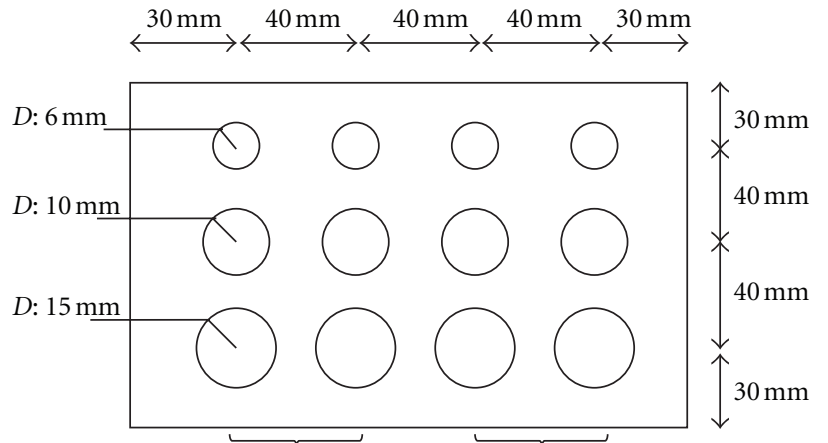

Sample 1 Layers 1 and 2 (155 $\mu$ m deep) Layers 2 and 3 ( $310 \mu \mathrm{m}$ deep) Sample 2 Layers 5 and 6 (775 $\mu \mathrm{m}$ deep) Layers 6 and 7 (930 $\mu \mathrm{m}$ deep) Sample 3 Layers 9 and 10 (1.4 mm deep) Layers 10 and 11 ( $1.55 \mathrm{~mm}$ deep)

Figure 1: Sample layouts with man-made delaminations.

under test; in Section 3, the four experimental systemsPEC stimulated thermography, flash thermography, UT/EC scanning system are illustrated; in Section 4, experimental results using individual systems are reported and compared. Section 5 summarises the work and looks forward towards future work.

\section{Samples Preparation}

20-layered CFRP samples (CYCOM970/T300) are used. The dimensions of the samples are $180 \times 140 \times 3.1 \mathrm{~mm}^{3}$. The man-made delaminations are manufactured by inserting a two-layered polytetrafluoroethylene film (of thickness $0.1 \mathrm{~mm}$ for each layer) between two fibre layers. The diameters $\mathrm{D}$ of the delaminations are $6 \mathrm{~mm}, 10 \mathrm{~mm}$, and $15 \mathrm{~mm}$, respectively and the delaminations are manufactured at the interface of $1 \mathrm{st}-2 \mathrm{nd}, 2 \mathrm{nd}-3 \mathrm{rd}$, 5th-6th, 6th-7th, 9th10th, and 10th-11th layers, respectively.

The sample layouts with delaminations are shown in Figure 1. Delaminations with 3 different diameters and 6 different depths $(155 \mu \mathrm{m}, 310 \mu \mathrm{m}, 775 \mu \mathrm{m}, 930 \mu \mathrm{m}, 1395 \mu \mathrm{m}$, and $1550 \mu \mathrm{m}$, resp.) are manufactured in three samples. Samples 1-3 are manufactured by Beijing Institute of Aeronautical Material.

\section{Experiment Systems}

To investigate the CFRP samples with man-made delaminations, four experimental systems are used at NUAA, which are PEC-stimulated thermography, flash thermography, and UT and EC scanning systems.

3.1. PEC-Stimulated Thermography System. Figure 2(a) shows the PEC-stimulated thermography system setup. HB-X5K high frequency heater with a work head linked to a coil from Wuxi Gaopin Technology Co., Ltd is used for pulsed eddy current excitation at NUAA. The heater provides a maximal $2 \mathrm{~kW}$ output at $320 \mathrm{kHz}$. The diameter of copper hollow is $2.08 \mathrm{~mm}$ and the outer diameter of circular coil 


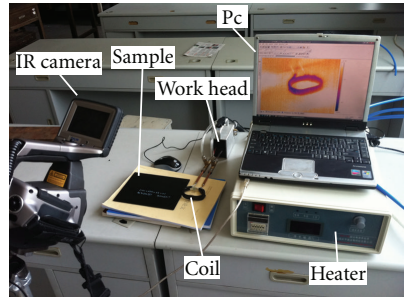

(a)

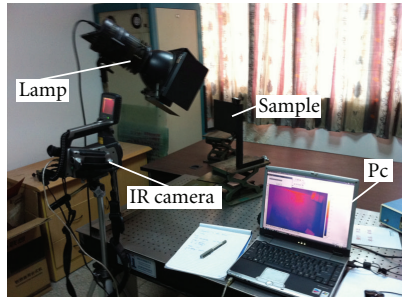

(b)

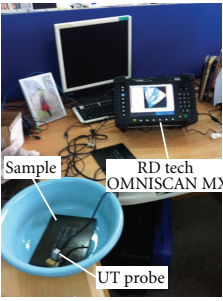

(c)

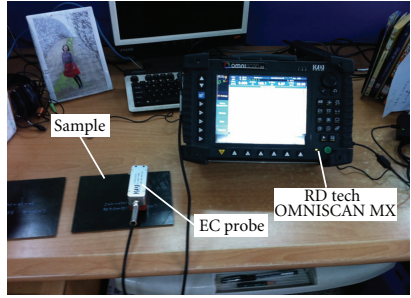

(d)

Figure 2: Experimental systems at NUAA: (a) PEC-stimulated thermography; (b) flash thermography; (c) UT scan; (d) EC scan.

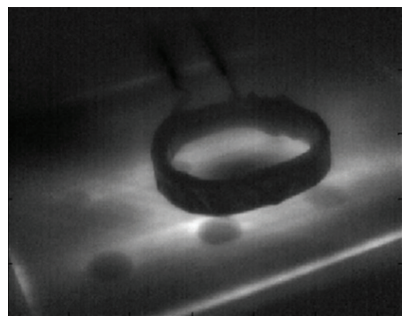

(a)

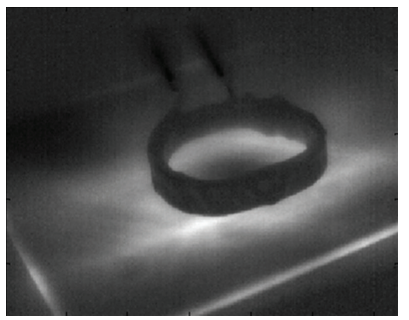

(b)

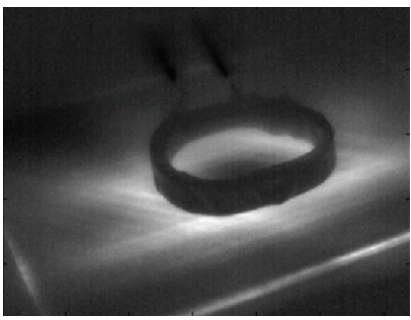

(c)

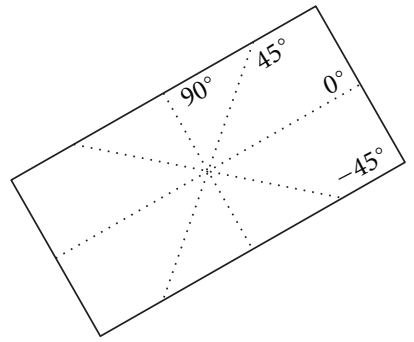

(d)

Figure 3: Thermal images at maximum heating (1s): (a) sample 1; (b) sample 2; (c) sample 3; (d) fibre orientation definition.

is approximately $50 \mathrm{~mm}$. A Flir ThermaCAM S65 is used to record thermal images and videos. The IR camera has a maximum full frame rate of $50 \mathrm{~Hz}$, providing 1 frame every $20 \mathrm{~ms}$. In contrast to the system built at Newcastle-Bath universities, the low-end IR camera with lower frame rates of $50 \mathrm{~Hz}$ comparing to $383 \mathrm{~Hz}$ in previous work, a battery and thermal video memory card is used at NUAA. Hopefully, this system can be suitable for offshore inspection. Therefore, without a water-cooling system for the coil, the recording period for one inspection is investigated to avoid the overheating on coil to affect the results.

3.2. Flash Thermography System. A flash lamp with $1 \mathrm{~kW}$ output power is used as heat source. A switch control unit is applied to control the heating duration from the lamp, as shown in Figure 2(b). The Flir ThermaCAM S65 is used to record thermal images and videos.

3.3. Ultrasonic and Eddy Current Scanning System. Ultrasonic and eddy current scanning using RD tech OMNISCAN MX on the samples are conducted at NUAA. It can be used in phased array acquisition module for UT scanning and eddy cureent array acquisition module for EC scanning. The ultrasonic probe, $\mathrm{RD}$ tech SA1-N45S (4 by 4 sensor array in the area of $30 \mathrm{~mm} \times 30 \mathrm{~mm}$ ), works at $5 \mathrm{MHz}$. The probe's refracted angle is $45^{\circ}$ for angle beam inspection from $30^{\circ}$ to $70^{\circ}$ using shear wave. The sound velocity in the sample is approximately $3100 \mathrm{~m} / \mathrm{s}$; EC array probe, RD tech SAA-056$005-016$ is used for EC scanning. The EC probe consists of 8by-2-coil array, working from $1 \mathrm{kHz}$ to $25 \mathrm{kHz}$ with $3.5 \mathrm{~mm}$ spatial resolution. The UT and EC scan system are shown in Figures 2(c) and 2(d), respectively.

\section{Experimental Results}

4.1. PEC-Stimulated Thermography Results. One-second heating period followed by two-second cooling is applied when the maximum power output of $2 \mathrm{~kW}$. The $15 \mathrm{~mm}$ diameter delaminations in samples 1,2 , and 3 are investigated. Delaminations at $155 \mu \mathrm{m}$ and $310 \mu \mathrm{m}$ deep can be seen as dark circles in Figure 3(a). In Figure 3(b), the delaminations at $775 \mu \mathrm{m}$ and $930 \mu \mathrm{m}$ deep are observed on the lower left and right to the coil, respectively. Delaminations at $1395 \mu \mathrm{m}$ and $1550 \mu \mathrm{m}$ deep in sample 3 are not observed in raw thermal images/videos.

Delaminations lead little distortion on eddy current distribution since eddy currents parallel to the layers have little interaction with the delaminations, which is not sensitive enough for EC scanning system reported in Section 4.4. The heat is generated mainly in $0^{\circ}$ and $-45^{\circ}$ (the direction is defined as shown in Figure 3(d) by the eddy currents induced by the inductor and they propagate in these two directions). Since the electric and thermal conductivities are largest along the fibre orientation, it can be known that the fibre orientations in 1st and 2nd layers are $-45^{\circ}$ and $0^{\circ}$. The delamination, as a thermal barrier, hinders heat propagation mainly in $0^{\circ}$ and $-45^{\circ}$ directions, which results in a hot spot on the delamination edge and a cool spot on the delamination region. Comparing the results from eddy current scanning discussed in Section 4.4, it can be seen that the heat diffusion is the main cause of heat generation at delaminations using PEC-stimulated thermography, allowing us to detect fibre breakage through these thermal images in advance. In addition, heat diffusion along fibres in each layer is evaluated using PEC-stimulated thermography. 
(e)

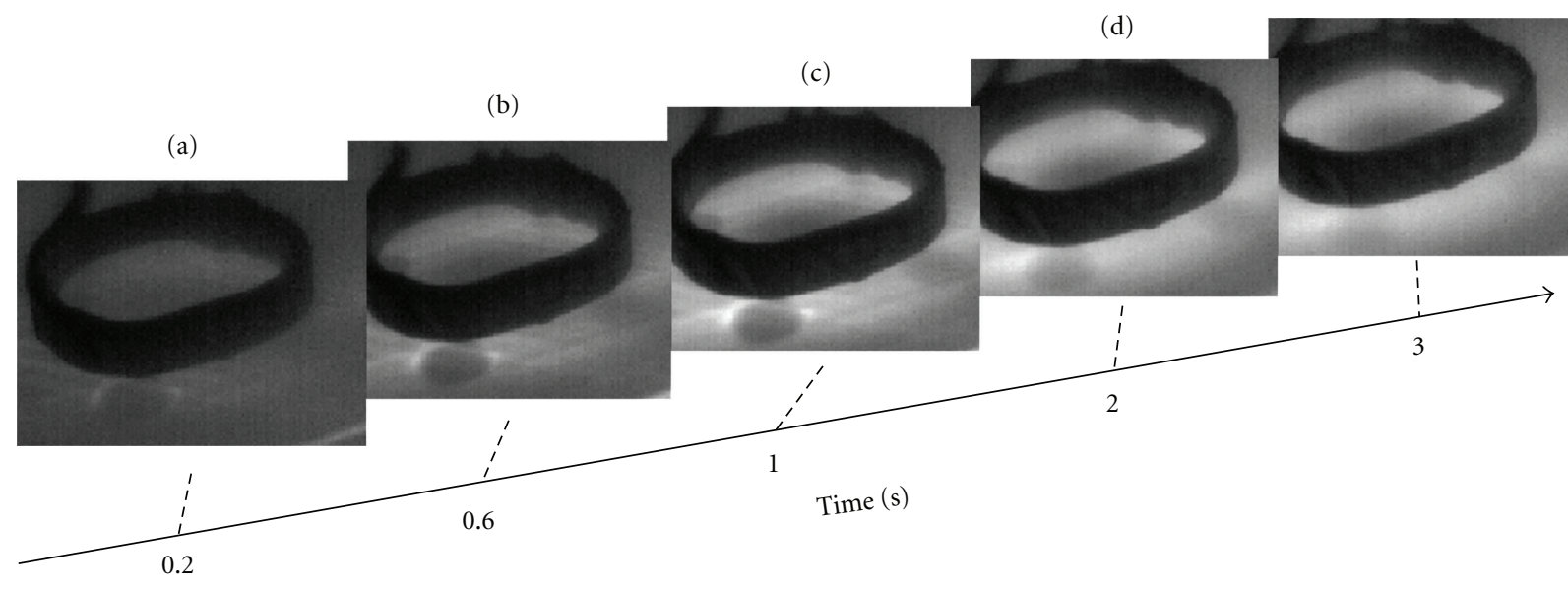

Figure 4: Thermal images for sample 1 at (a) $0.2 \mathrm{~s}$; (b) $0.6 \mathrm{~s}$; (c) $1 \mathrm{~s}$; (d) $2 \mathrm{~s}$; (e) $3 \mathrm{~s}$.

In Figure 4, the thermal images at different times of heating or cooling phase are shown. At the beginning of heating $(0.2 \mathrm{~s})$, the edge of $155 \mu \mathrm{m}$ deep delamination at lower left to the coil is highlighted, whilst the $310 \mu \mathrm{m}$ deep delamination at the right bottom is not visible (Figure $4(\mathrm{a})$ ). And as heating time increases, the contrast between delamination and sound area increases and the $310 \mu \mathrm{m}$ deep delamination can be noticed (Figure 4(b)). Till the maximum heating (1s), the contrast between delaminations and sound area becomes the biggest (Figure 4(c)). After that, the heat diffusion in cooling phase blurs the images (Figures 4(d) and 4(e)). In Figure 4, it shows the shallower delamination can be observed earlier and the temperature contrast is larger. Different layer structure and fibre orientation can be easily visualised through the video sequences, which is in contrast to the surface inspection using flash thermography results below.

4.2. Flash Thermography Results. The temperature images using flash thermography for samples 1, 2, and 3 are shown in Figures 5(a)-5(c), respectively, after a period of 5-second heating. From these results, delaminations in both samples 1 and 2 are observed but are not in sample 3. Due to the surface heating by flash thermography, heat propagates from the surface to the rear side. Delaminations, as thermal barriers, stop heat diffusion and reflect the heat back to the surface, which results in higher temperatures at delaminations than in nondefected regions. Therefore, flash thermography provides heat diffusion information in the depth direction rather than in the direction of fibre orientations in each layer using PEC-stimulated thermography.

4.3. Ultrasonic Scanning Results. The reflected ultrasonic signals and C-scan images on each delamination with $15 \mathrm{~mm}$ diameter and varied depths are shown in Figure 6. The probe's refracted angle is $45^{\circ}$ for angle beam inspection from $30^{\circ}$ to $70^{\circ}$ using shear wave. In Figure 6(a), we can observe many reflections in the nondefected region, which is caused by the multilayer structure of CFRP. The delaminations are identified by high reflection amplitude of ultrasound signals and shown as red regions in the images of interfaces of delamination and CFRP materials, as shown in Figures 6(b)-6(g). Due to the thin-layered structure, UT does not provide accurate depth information: the detected depths of delaminations do not agree with the actual values, which can be seen in Figure 6(h). Besides, the measured diameters of the delaminations vary at different depths or positions, which lead to inaccurate indications of the dimension and location of the delaminations. The experiment shows the limitations of UT for composite materials that (1) multiple reflection and scattering in composites; (2) large penetration and scattering loss; (3) inaccurate measurement for thin sample; (4) contact and liquid coupling are required.

To achieve better visualisation of the defects, guided wave $\mathrm{C}$-scans using a phase array can reduce the multiple reflections and scattering for accurate depth measurement. However, the scanning time and data amount could increase significantly, which does not satisfy the requirement for online monitoring or structural health monitoring, compared with PEC-stimulated or flash thermography.

4.4. Eddy Current Scanning Results. The eddy current scanning image for sample 1 is shown in Figure 7. The EC probe consists of 8-by-2-coil array, working from $1 \mathrm{kHz}$ to $25 \mathrm{kHz}$ with $3.5 \mathrm{~mm}$ spatial resolution. No significant patterns of delaminations are observed on the samples. Results show that the sensitivity of the EC scanning system is not high enough to detect the eddy currents at the delamination of the composite with low conductivity.

\subsection{Comparison and Discussion}

(1) Detection Ability for Detected Depth. From the experiments, the ultrasonic scanning approach detects the delaminations in all of the samples; PEC-stimulated thermography 


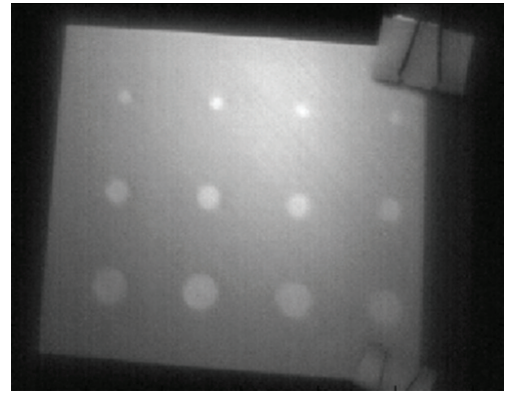

(a)

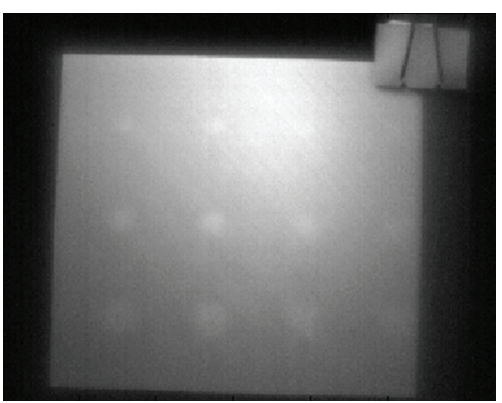

(b)

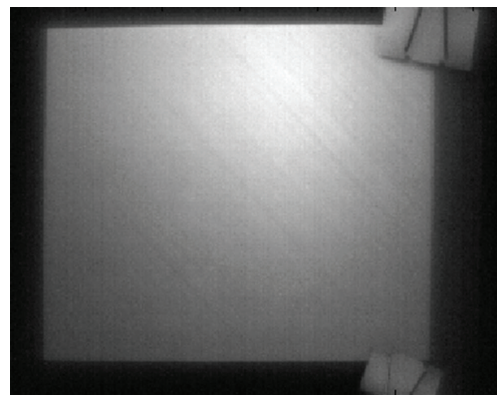

(c)

FIgURE 5: Flash thermography images at maximum heating (5 seconds): (a) sample 1; (b) sample 2; (c) sample 3.

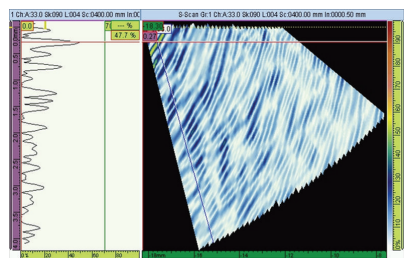

(a)

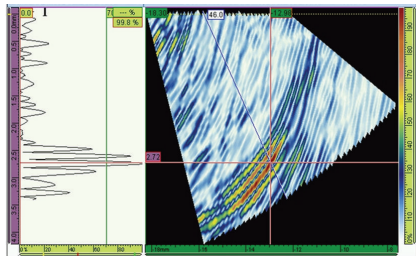

(e)

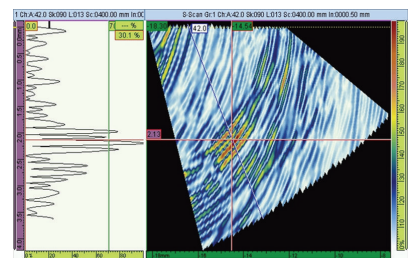

(b)

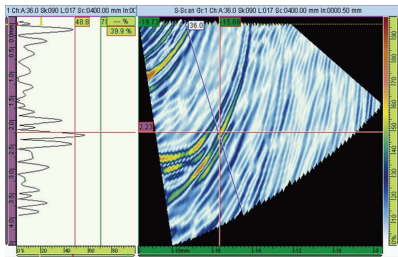

(f)

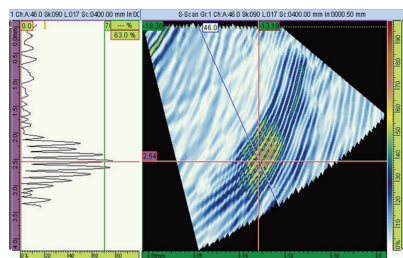

(c)

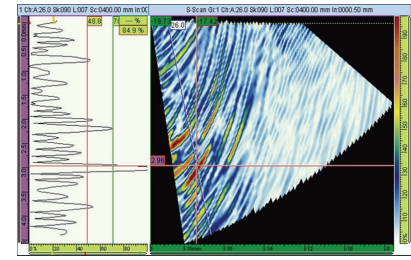

(g)

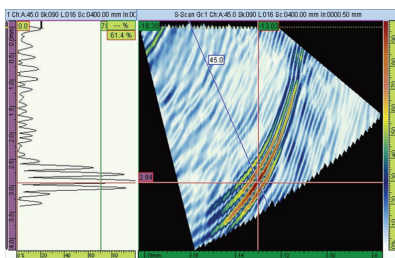

(d)

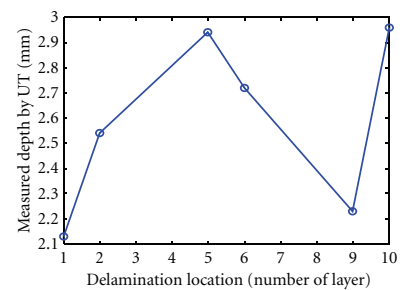

(h)

FIGURE 6: UT scanning results: (a) no delamination; (b) $155 \mu \mathrm{m}$ deep delamination; (c) $310 \mu \mathrm{m}$ deep delamination, (d) $775 \mu \mathrm{m}$ deep delamination; (e) $930 \mu \mathrm{m}$ deep delamination; (f) $1395 \mu \mathrm{m}$ deep delamination; (g) $1550 \mu \mathrm{m}$ deep delamination; (h) actual and measured delamination depth.

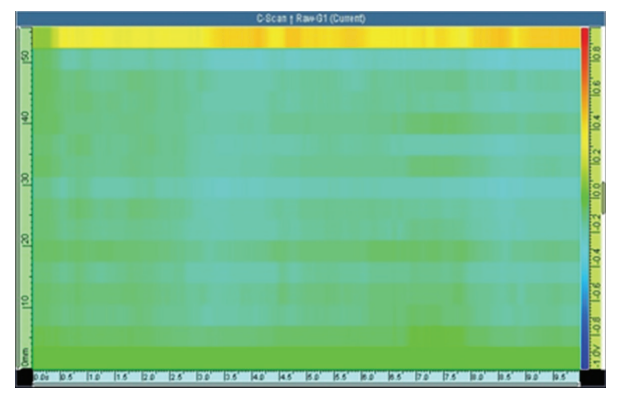

FIGURE 7: EC scanning image of sample 1.

and flash thermography detect delaminations in samples 1 and 2 only, while EC scanning detected no delaminations. Therefore, UT scanning has the best detection ability amongst the four methods.

(2) Fibre Orientation. PEC-stimulated thermography can be used to observe fibre orientations through thermal images. The highlighted lines in the sample surface indicate the fibres in the surface and subsurface layers. UT scanning and flash thermography both fail to show fibre orientation.

(3) Visualisation of Defects. PEC-stimulated thermography and flash thermography can provide good visualisation of a defect, allowing us to know its shape and dimensions (except thickness). Although UT scanning can also provide imaging by the way of a reconstruction algorithm, it is timeconsuming and the image suffers from massive attenuation, multiple reflection, and scattering of the ultrasound waves.

(4) Inspection Time and Cost. PEC-stimulated thermography and flash thermography can provide the inspection within second scale to observe defects, whilst UT scanning requires minutes or hours with a large amount of data. These two thermographic methods are superior to satisfy the requirement for online monitoring or structural health monitoring. Besides, the cost of UT scanning system and probe itself is much higher than PEC-stimulated thermography or flash thermography. 
TABLE 1: Comparison of PEC-stimulated thermography, flash thermography, and UT/EC scanning.

\begin{tabular}{lccc}
\hline & PEC stimulated thermography & Flash thermography & UT scanning \\
\hline & & & \\
& & Up to $930 \mu \mathrm{m}$ deep & Up to $1550 \mu \mathrm{m}$ deep \\
Image for sample 1 & Up to $930 \mu \mathrm{m}$ deep & No & No \\
Detected depth & Good & Good & Not good \\
Fibre orientation & Good & $\sim$ Seconds & Minutes to hours \\
Defect visualisation & $\sim$ Seconds & Low & High \\
Inspection time & Low & - \\
Cost & & -
\end{tabular}

The comparison of these four approaches investigated is summarised in Table 1.

\section{Conclusion and Future Work}

In this paper, man-made delaminations in samples 1 and 2 at $155 \mu \mathrm{m}, 310 \mu \mathrm{m}, 775 \mu \mathrm{m}$, and $930 \mu \mathrm{m}$ deep have been observed through the new developed PEC-stimulated thermography at NUAA system. However, deeper delaminations in sample 3 ( $1395 \mu \mathrm{m}$ and $1550 \mu \mathrm{m}$ deep) could not be seen clearly from the raw thermal videos. Both UT/EC scanning and flash thermography have also been carried out at NUAA for comparison. Results showed (1) only enables PECstimulated thermography to observe the fibre orientation for surface and subsurface layers, giving the potential for minor defect detection for example, fibre breakage; (2) although PEC-stimulated thermography and flash thermography did not detect the delamination deeper than $930 \mu \mathrm{m}$, they offer rapid inspection and better visualisation of delaminations from transient thermal images/videos.

The UT experiment shows the limitations of this approach for composite materials, due to (1) multiple reflections and scattering in composites, (2) inaccurate measurement for thin samples, (3) liquid coupling is required. PECstimulated thermography and flash thermography can be considered as two powerful approaches for delamination detection. In concern with fibre orientation evaluation and other typical defects in composite materials, for example, impact damages, cracks, PEC-stimulated thermography is more sensitive to those defects, especially cracks [23]. Therefore, PEC-stimulated thermography with low specification of camera has been proven as a good candidate for CFRP delamination detection, where thermal and electrical conductivity are evaluated. Different defects can be evaluated using PEC-stimulated thermography systems in the future.

In future work, more powerful excitation for deeper delamination detection: pulse width, inductor geometry, and directions for PEC-stimulated thermography will be investigated to detect deeper delaminations. Post-image/video processing to enhance the contract of delamination including removal of direct heating from excitation coils and background in the images/videos for thermography and feature extraction for the transient image response and patterns will be further considered and developed.

\section{Acknowledgments}

This study is funded by Engineering and Physical Sciences Research Council (EPSRC), UK (EP/F06151X/1), and FP7 HEMOW Project (FP7-PEOPLE-2010-IRSES, 269202). The authors would like to thank Professor Yupeng Tian and Associate Professor Ping Wang from Nanjing University of Aeronautics and Astronautics, China for their useful discussions and Mr. Zhen Shi from Nanjing University of Aeronautics and Astronautics, China for the help on UT/EC scanning experiments. In addition, the authors also would like to thank Beijing Institute of Aeronautical Material, China for providing the samples used in the experiments.

\section{References}

[1] T. E. Michaels and B. D. Davidson, "Ultrasonic inspection detects hidden damage in composites," Advanced Materials and Processes, vol. 143, no. 3, pp. 34-38, 1993.

[2] H. Kocznarech, "Ultrasonic detection of damage in carbon fibre reinforced plastics," Journal of Composite Materials, vol. 29, pp. 59-95, 1995.

[3] D. E. Chimenti and A. H. Nayfeh, "Leaky Lamb waves in fibrous composite laminates," Journal of Applied Physics, vol. 58, no. 12, pp. 4531-4538, 1985.

[4] S. H. Rhee, J. K. Lee, and J. J. Lee, “The group velocity variation of Lamb wave in fiber reinforced composite plate," Ultrasonics, vol. 47, no. 1-4, pp. 55-63, 2007.

[5] E. Jasiüniené, R. Raišutis, R. Šliteris et al., "NDT of wind turbine blades using adapted ultrasonic and radiographic techniques," Insight, vol. 51, no. 9, pp. 477-483, 2009.

[6] A. Ghoshal, W. N. Martin, M. J. Schulz, A. Chattopadhyay, W. H. Prosser, and H. S. Kim, "Health monitoring of composite plates using acoustic wave propagation, continuous sensors and wavelet analysis," Journal of Reinforced Plastics and Composites, vol. 26, no. 1, pp. 95-112, 2007.

[7] M. Giordano, A. Calabro, C. Esposito, A. D'Amore, and L. Nicolais, "An acoustic-emission characterization of the failure modes in polymer-composite materials," Composites Science and Technology, vol. 58, no. 12, pp. 1923-1928, 1998. 
[8] A. Sophian, G. Y. Tian, D. Taylor, and J. Rudlin, "Electromagnetic and eddy current NDT: a review," Insight, vol. 43, no. 5, pp. 302-306, 2001.

[9] R. Grimberg, D. Prémel, A. Savin, Y. Le Bihan, and D. Placko, "Eddy current holography evaluation of delamination in carbon-epoxy composites,” Insight, vol. 43, no. 4, pp. 260-264, 2001.

[10] S. Kharkovsky, J. T. Case, M. A. Abou-Khousa, R. Zoughi, and F. L. Hepburn, "Millimeter-wave detection of localized anomalies in the space shuttle external fuel tank insulating foam," IEEE Transactions on Instrumentation and Measurement, vol. 55, no. 4, pp. 1250-1257, 2006.

[11] C. Ibarra-Castanedo, J. M. Piau, S. Guilbert et al., "Comparative study of active thermography techniques for the nondestructive evaluation of honeycomb structures," Research in Nondestructive Evaluation, vol. 20, no. 1, pp. 1-31, 2009.

[12] N. P. Avdelidis and D. P. Almond, "Through skin sensing assessment of aircraft structures using pulsed thermography," NDT and E International, vol. 37, no. 5, pp. 353-359, 2004.

[13] N. P. Avdelidis, C. Ibarra-Castanedo, X. Maldague, Z. P. Marioli-Riga, and D. P. Almond, "A thermographic comparison study for the assessment of composite patches," Infrared Physics and Technology, vol. 45, no. 4, pp. 291-299, 2004.

[14] G. Busse and P. Eyerer, "Thermal wave remote and nondestructive inspection of polymers," Applied Physics Letters, vol. 43, no. 4, pp. 355-357, 1983.

[15] R. Mulaveesala and V. S. Ghali, "Cross-correlation-based approach for thermal non-destructive characterisation of carbon fibre reinforced plastics," Insight, vol. 53, no. 1, pp. 34-36, 2011.

[16] N. P. Avdelidis, B. C. Hawtin, and D. P. Almond, "Transient thermography in the assessment of defects of aircraft composites," NDT and E International, vol. 36, no. 6, pp. 433-439, 2003.

[17] S. M. Shepard, J. Hou, J. R. Lhota, and J. M. Golden, "Automated processing of thermographic derivatives for quality assurance," Optical Engineering, vol. 46, no. 5, Article ID 051008, 2007.

[18] V. P. Vavilov, D. A. Nesteruk, and V. S. Khorev, "IR thermographic NDT research at Tomsk Polytechnic University, Siberia, Russia," in 50th Annual Conference of The British Institute of Non-Destructive Testing, Telford, UK, 2011.

[19] I. Zainal Abidin, G. Yun Tian, J. Wilson, S. Yang, and D. Almond, "Quantitative evaluation of angular defects by pulsed eddy current thermography," NDT and E International, vol. 43, no. 7, pp. 537-546, 2010.

[20] M. Noethen, K. J. Wolter, and N. Meyendorf, "Surface crack detection in ferritic and austenitic steel components using inductive heated thermography," in 33rd International Spring Seminar on Electronics Technology (ISSE '10), pp. 249-254, May 2010.

[21] B. Oswald-Tranta and G. Wally, "Thermo-inductive surface crack detection in metallic materials," in 9th European Conference on NDT, Berlin, Germany, 2006.

[22] S. Yang, G. Y. Tian, I. Z. Abidin, and J. Wilson, "Simulation of edge cracks using pulsed eddy current stimulated thermography," Journal of Dynamic Systems, Measurement and Control, vol. 133, no. 1, Article ID 011008, 2011.

[23] L. Cheng and G. Y. Tian, "Surface crack detection for carbon fiber reinforced plastic (CFRP) materials using pulsed eddy current thermography," IEEE Sensors Journal, vol. 11, no. 12, pp. 3261-3268, 2011.

[24] B. Ramdane, D. Trichet, M. Belkadi, and J. Fouladgar, "3-D numerical modeling of the thermo-inductive technique using shell elements," IEEE Transactions on Magnetics, vol. 46, no. 8, Article ID 5512872, pp. 3037-3040, 2010. 

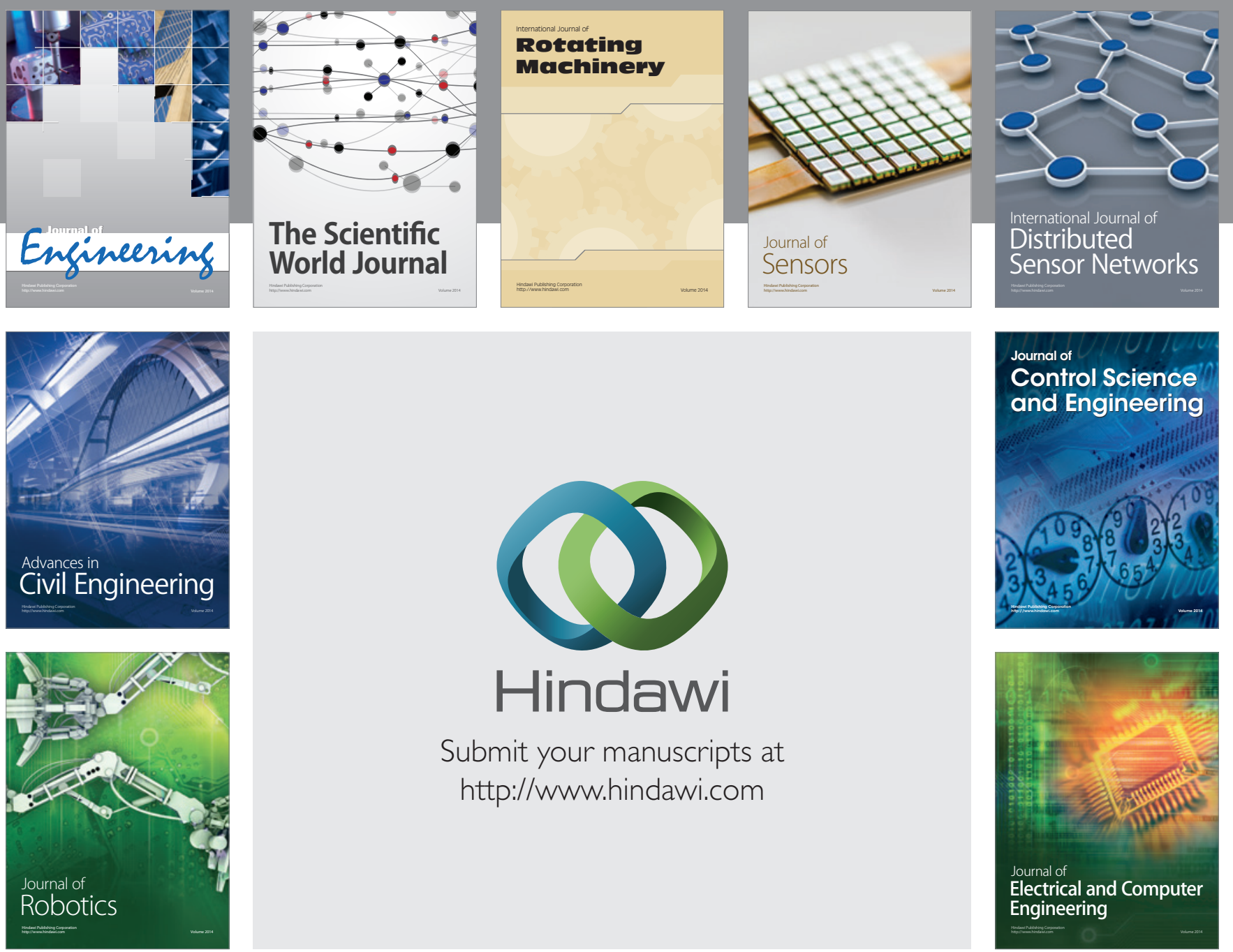

Submit your manuscripts at

http://www.hindawi.com
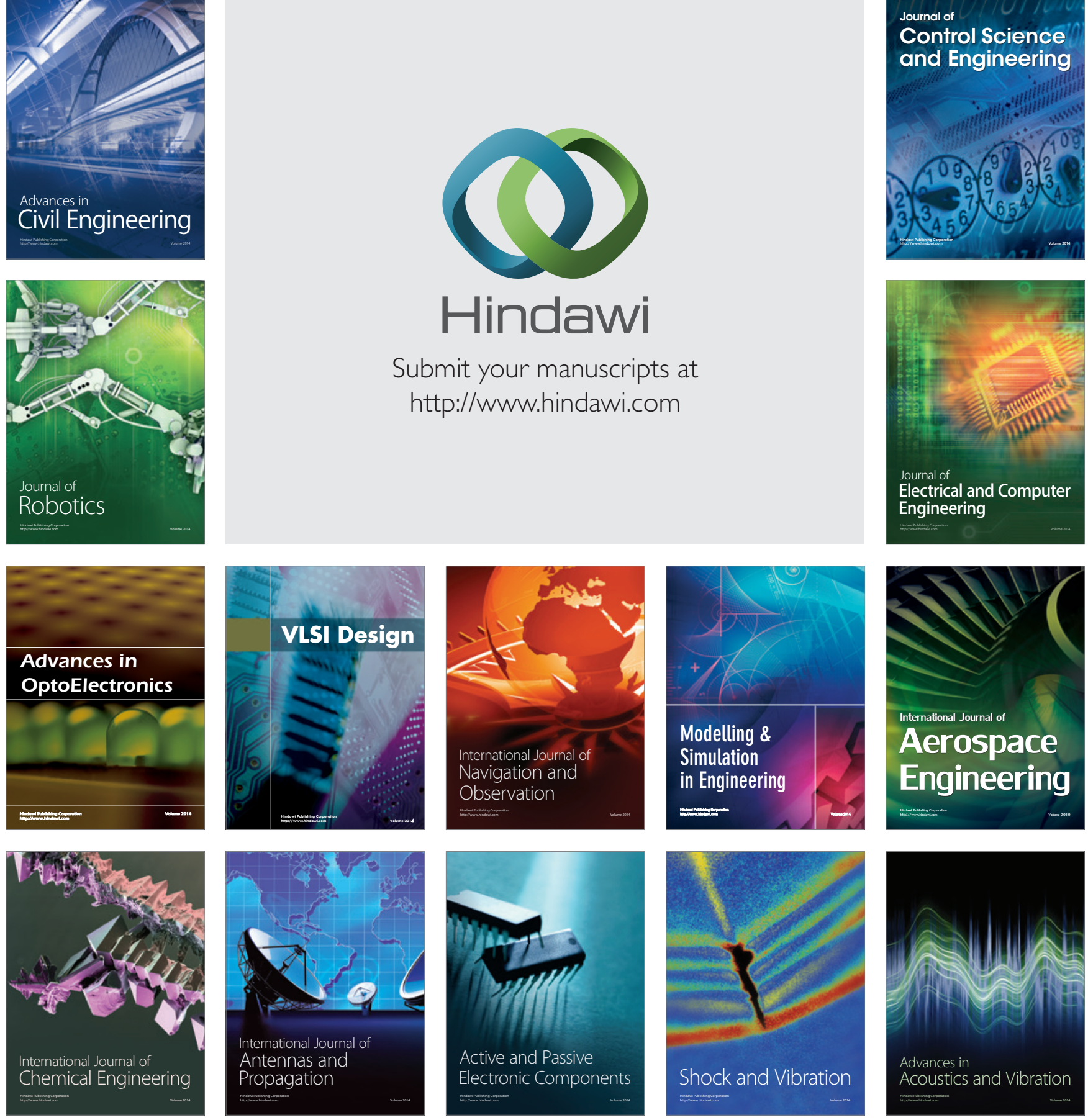